\title{
The shortest Th-Th distance from a new type of quadruple bond
}

DOI:

10.1039/C7CP00113D

\section{Document Version}

Accepted author manuscript

Link to publication record in Manchester Research Explorer

\section{Citation for published version (APA):}

Hu, H., \& Kaltsoyannis, N. (2017). The shortest Th-Th distance from a new type of quadruple bond. Physical Chemistry Chemical Physics, 19, 5070-5076. https://doi.org/10.1039/C7CP00113D

\section{Published in:}

Physical Chemistry Chemical Physics

\section{Citing this paper}

Please note that where the full-text provided on Manchester Research Explorer is the Author Accepted Manuscript or Proof version this may differ from the final Published version. If citing, it is advised that you check and use the publisher's definitive version.

\section{General rights}

Copyright and moral rights for the publications made accessible in the Research Explorer are retained by the authors and/or other copyright owners and it is a condition of accessing publications that users recognise and abide by the legal requirements associated with these rights.

\section{Takedown policy}

If you believe that this document breaches copyright please refer to the University of Manchester's Takedown Procedures [http://man.ac.uk/04Y6Bo] or contact uml.scholarlycommunications@manchester.ac.uk providing relevant details, so we can investigate your claim.

\section{OPEN ACCESS}



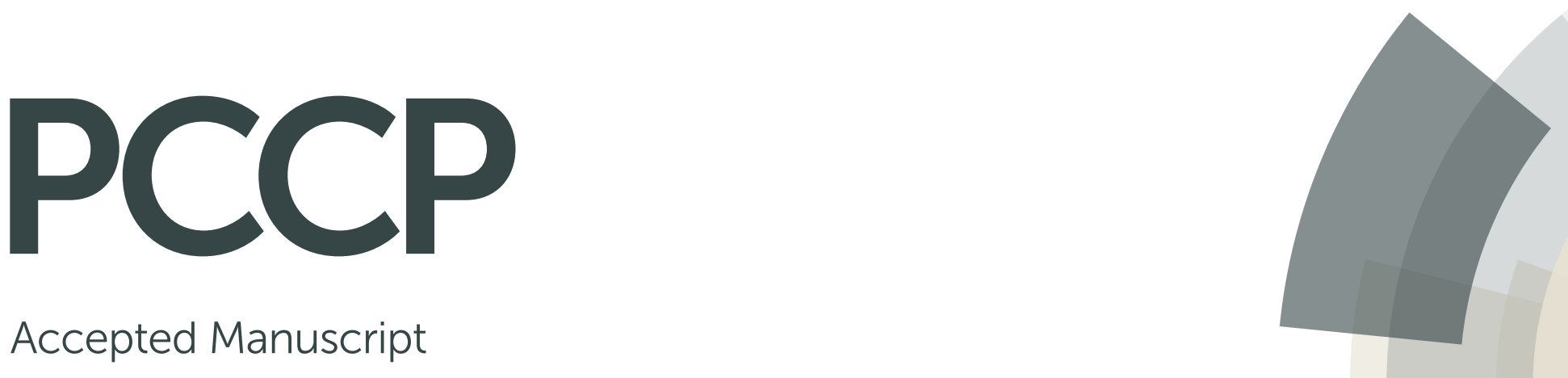

Accepted Manuscript

This article can be cited before page numbers have been issued, to do this please use: $\mathrm{H}$. Hu and N. Kaltsoyannis, Phys. Chem. Chem. Phys., 2017, DOI: 10.1039/C7CP00113D.

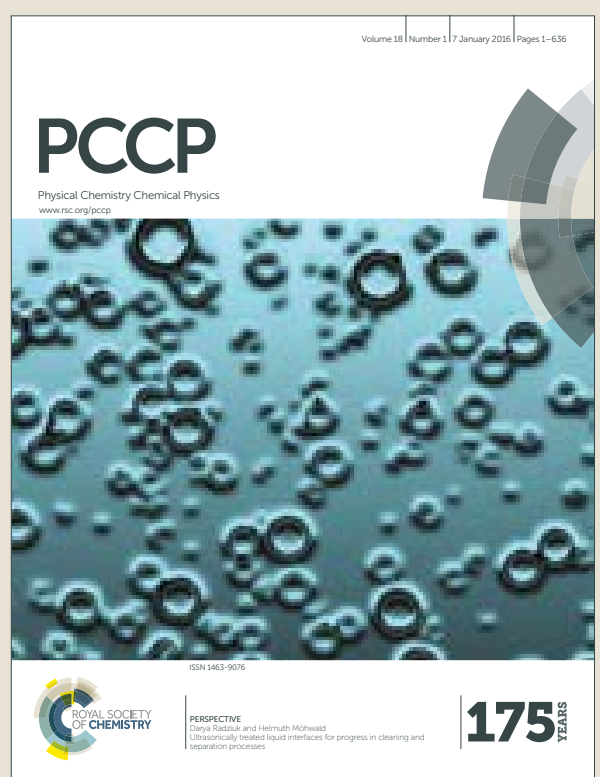

This is an Accepted Manuscript, which has been through the Royal Society of Chemistry peer review process and has been accepted for publication.

Accepted Manuscripts are published online shortly after acceptance, before technical editing, formatting and proof reading. Using this free service, authors can make their results available to the community, in citable form, before we publish the edited article. We will replace this Accepted Manuscript with the edited and formatted Advance Article as soon as it is available.

You can find more information about Accepted Manuscripts in the author guidelines.

Please note that technical editing may introduce minor changes to the text and/or graphics, which may alter content. The journal's standard Terms \& Conditions and the ethical guidelines, outlined in our author and reviewer resource centre, still apply. In no event shall the Royal Society of Chemistry be held responsible for any errors or omissions in this Accepted Manuscript or any consequences arising from the use of any information it contains. 


\title{
The shortest Th-Th distance from a new type of quadruple bond
}

\author{
Han-Shi Hu and Nikolas Kaltsoyannis \\ School of Chemistry, The University of Manchester, Oxford Road, Manchester M13 9PL, UK \\ Email: nikolas.kaltsoyannis@manchester.ac.uk
}

\begin{abstract}
Compounds featuring unsupported metal-metal bonds between actinide elements remain highly sought after yet confined experimentally to inert gas matrix studies. Notwithstanding this paucity, actinide-actinide bonding has been the subject of extensive computational research. In this contribution, high level quantum chemical calculations at both the scalar and spin-orbit levels are used to probe the Th-Th bonding in a range of zero valent systems of general formula LThThL. Several of these compounds have very short Th-Th bonds arising from a new type of Th-Th quadruple bond with a previously unreported electronic configuration featuring two unpaired electrons in 6d-based $\delta$ bonding orbitals. $\mathrm{H}_{3} \mathrm{AsThThAsH}_{3}$ is found to have the shortest Th-Th bond yet reported $(2.590 \AA)$. The $\mathrm{Th}_{2}$ unit is a highly sensitive probe of ligand electron donor/acceptor ability; we can tune the $\mathrm{Th}$ Th bond from quadruple to triple, double and single by judicious choice of the L group, up to $2.888 \AA$ for singly-bonded ONThThNO.
\end{abstract}

\section{Introduction}

The chemical bond is one of the most central concepts in chemistry, ${ }^{1}$ and metal-metal bonding is a particularly rich and well-studied phenomenon. While there are numerous examples of compounds with metal-metal bonds built from main group and d transition elements, ${ }^{2,3}$ only a very few actinideactinide bonds are known, in systems stabilised by noble gas matrices. ${ }^{4}$ The nature of the bonds formed between actinide metals is of fundamental importance in deepening our understanding of chemical bonding in general, ${ }^{5}$ and more specifically of the electronic structure and the coordinative diversity of the $5 \mathrm{f}$ elements, ${ }^{6}$ where differences exist from their main group, $\mathrm{d}$ block and lanthanide counterparts. ${ }^{7}$ Furthermore, extensive studies of the properties of actinide compounds are required given the central role of these elements in the nuclear fuel cycle. ${ }^{8}$ By contrast to the $4 \mathrm{f}$ elements, many actinides have access to a wide range of formal oxidation states, ${ }^{9,10}$ and this range has very recently been enhanced with the reports of thorium and uranium in oxidation state $\mathrm{II},{ }^{11,12}$ a rare development as the formal oxidation states for the majority of elements have been well established for many years. ${ }^{1314}$ These exciting achievements offer additional routes into low oxidation state actinide chemistry, and there is potential for low oxidation state actinides to form direct An-An bonds, perhaps even with multiple bonds.

The synthesis of compounds containing direct An-An bonds is very challenging, as the metals preferentially connect to main group-based ligands instead of other actinides. ${ }^{15,16,17,18,19,20}$ Nevertheless, computational quantum chemistry has been extensively employed to study An-An bonded systems. In addition to the seminal investigation of $\mathrm{U}_{2}$ in $2005,{ }^{5}$ molecules reported include $\mathrm{An}_{2}(\mathrm{An}=\mathrm{Ac}, \mathrm{Th}, \mathrm{Pa}$ and $\mathrm{U}),{ }^{21} \mathrm{H}_{2} \mathrm{UUH}_{2}$ (diuranium hydrides), ${ }^{4} \mathrm{HThThH},{ }^{22} \mathrm{PhUUPh}^{23}{ }^{23} \mathrm{U}_{2}{ }^{2+},{ }^{24}\left[\mathrm{An}_{2} \mathrm{X}_{8}\right]^{2-}(\mathrm{An}=\mathrm{U}, \mathrm{Np}, \mathrm{Pu}$; $\mathrm{X}=\mathrm{Cl}, \mathrm{Br}, \mathrm{I}),{ }^{25} \mathrm{U}_{2} \mathrm{X}_{6}\left(\mathrm{X}=\mathrm{Cl}, \mathrm{F}, \mathrm{OH}, \mathrm{NH}_{2}, \mathrm{CH}_{3}\right),{ }^{26} \mathrm{U}_{2}(\mathrm{OCHO})_{4}, \mathrm{U}_{2}(\mathrm{OCHO})_{6}$, and $\mathrm{U}_{2}(\mathrm{OCHO})_{4} \mathrm{Cl}_{2}$ (diuranium carboxylates), ${ }^{27} \mathrm{An}_{2}\left(\mathrm{C}_{8} \mathrm{H}_{8}\right)_{2}(\mathrm{An}=\mathrm{Th}, \mathrm{Pa}, \mathrm{U}, \mathrm{Np})^{28}$ and $\mathrm{An}_{2} \mathrm{Cp}_{2}{ }_{2}\left(\mathrm{Cp}^{*}=\mathrm{C}_{5}\left(\mathrm{CH}_{3}\right)_{5}, \mathrm{An}=\right.$ $\mathrm{Th}-\mathrm{Pu}$ ) (actinide dimetallocenes). ${ }^{29}$ Multiple metal-metal bonding has been found up to a quintuple maximum. Typically, the $7 \mathrm{~s}$ and $6 \mathrm{~d}$ orbitals are strongly implicated in these bonds, with additional contributions from the 5f. The An-An bond lengths reported to date are collected in Table S1 in the 
supplementary information, from which it is noticeable that the introduction of ligands can shorten the An-An bond length compared with naked $\mathrm{An}_{2}$, e.g. $\mathrm{U}_{2}$ vs $\mathrm{U}_{2} \mathrm{H}_{2}$.

The thorium atom has a triplet ground state, with electronic configuration $[R n] 6 \mathrm{~d}^{2} 7 \mathrm{~s}^{2}$. The energetic cost of unpairing the $7 \mathrm{~s}$ electrons to form quintet $[\mathrm{Rn}] 6 \mathrm{~d}^{3} 7 \mathrm{~s}^{1}$ is only $0.69 \mathrm{eV},{ }^{21}$ and thorium thus has four electrons potentially available to form Th-Th bonds. To date, computationally studied compounds with direct $\mathrm{Th}-\mathrm{Th}$ bonds are limited to $\mathrm{Th}_{2}, \mathrm{HThThH}, \mathrm{Cp}^{*} \mathrm{ThThCp}^{*}$ and $\left(\mathrm{C}_{8} \mathrm{H}_{8}\right) \operatorname{ThTh}\left(\mathrm{C}_{8} \mathrm{H}_{8}\right)$. The latter three systems feature the metal in the Th(I), Th(I) and Th(II) oxidation states respectively. Straka and Pyykkö predicted that hydride coordination to $\mathrm{Th}_{2}$ (to make the $\mathrm{Th}(\mathrm{I})$ system HThThH) produces a $\sigma+2 \pi \mathrm{Th}$-Th triple bond with the $7 \mathrm{~s} \sigma_{\mathrm{g}}{ }^{2} 6 \mathrm{~d} \pi_{\mathrm{u}}{ }^{4}$ configuration. ${ }^{22} \mathrm{Th}_{2}$ is the only $\operatorname{Th}(0)-\operatorname{Th}(0)$ compound to have been previously considered; a quadruple $\mathrm{Th}-\mathrm{Th}$ bond with the ground configuration $7 \mathrm{~s} \sigma_{\mathrm{g}}{ }^{2} 6 \mathrm{~d} \pi_{\mathrm{u}}{ }^{4} 6 \mathrm{~d} \sigma_{\mathrm{g}}{ }^{1} 6 \mathrm{~d} \delta_{\mathrm{g}}{ }^{1}\left({ }^{3} \Delta_{\mathrm{g}}\right)$ was established. ${ }^{21}$ However, it was reported that there are 12 excited states within less than $1 \mathrm{eV}$, two of which $\left({ }^{1} \Delta_{\mathrm{g}}\right.$ and $\left.{ }^{3} \sum_{\mathrm{g}}{ }^{-}\right)$have shorter Th-Th bond lengths than the ground state. ${ }^{21}$ Recent 2-D fluorescence spectroscopy has detected $\mathrm{Th}_{2}$ in the gas phase and the measured vibrational constants are larger for excited states in comparison with that of the ground state (169 and $212 \mathrm{~cm}^{-1}$ vs $135 \mathrm{~cm}^{-1}$ ), ${ }^{30}$ suggesting that $\mathrm{Th}_{2}$ indeed has stronger Th-Th bonds in its excited states. In light of this theoretical and experimental evidence for stronger Th-Th bonds in low lying excited states, we wondered if it might be possible to induce a shorter ground state $\mathrm{Th}(0)-\mathrm{Th}(0)$ bond by judicious choice of ligand set, and here report computational evidence that this is indeed the case.

\section{Computational methods}

Geometry optimizations for all compounds were performed using density functional theory within the generalized gradient approximation (GGA) with the $\mathrm{PBE}^{31}$ exchange-correlation functional, as implemented in the ADF 2014.01 program. ${ }^{32}$ Slater type orbital basis sets of triple-zeta plus one or two polarization functions (TZP \& TZ2P) quality were employed; TZP for Th and TZ2P for all other elements. ${ }^{33}$ The frozen core approximation was used for all atoms except $\mathrm{H} ;\left[1 \mathrm{~s}^{2}\right]$ for $\mathrm{C}, \mathrm{N}$ and $\mathrm{O}$; $\left[1 s^{2}-2 p^{6}\right]$ for $P ;\left[1 s^{2}-3 p^{6}\right]$ for As; $\left[1 s^{2}-4 f^{14}\right]$ for Th. Scalar relativistic effects were taken into account by the zero-order-regular approximation (ZORA). ${ }^{34}$ Vibrational frequency calculations were carried out to verify that the structures were minima at the stationary points of the total energy surfaces.

$A b$ initio calculations on $\mathrm{H}_{3} \mathrm{PThThPH}_{3}$ were performed using the coupled-cluster approach with single, double and perturbative triple excitations $(\operatorname{CCSD}(\mathrm{T})),{ }^{35,36}$ and at the complete-active-space second order perturbation theory (CASPT2) level. ${ }^{37,38,39}$ These calculations were carried out with the Molpro 2015.1 program. ${ }^{40}$ Geometry optimizations were performed at both the $\operatorname{CCSD}(\mathrm{T})$ and CASPT2 levels. Spin-orbit coupling (SOC) was treated by a state-interacting method in the basis of state averaged-CASSCF wave functions, with $\operatorname{CCSD}(\mathrm{T})$ energies used for those wave functions, at the CASPT2(8e, 8o)-optimised ground state geometry. ${ }^{41,42}$ The Stuttgart energy-consistent relativistic pseudopotential ECP60MWB ${ }^{43,44,45}$ and the corresponding valence basis set was used for the Th atoms, and the Dunning polarized valence triple- $\zeta$ basis sets (cc-pVTZ) ${ }^{46,47,48}$ for the light atoms.

Natural Bond Orbital (NBO) ${ }^{49}$ and electron localization function (ELF) ${ }^{50}$ calculations were performed based on the TAPE15, FILE47 and TAPE21 files created by ADF 2014.01. No frozen core approximation was used in order to create the TAPE15 files. Quantum Theory of Atoms-in-Molecules $(\mathrm{QTAIM})^{51}$ analyses were performed using the AIMALL program package, with wfx files generated in the Gaussian 09, Rev. D.01 program. ${ }^{52}$ For the Gaussian single-point energy calculations using the PBE functional, the cc-pVDZ basis set was used for all atoms except Th, for which the Stuttgart 
energy-consistent relativistic pseudopotential ECP60MWB and the corresponding valence basis set was used.

\section{Results and discussion}

As noted in the Introduction, the two unpaired electrons in $\mathrm{Th}_{2}$ occupy the $6 \mathrm{~d} \sigma_{\mathrm{g}}$ and $6 \mathrm{~d} \delta_{\mathrm{g}}$ molecular orbitals (MOs) and it was our hope that we could tune the properties of these electrons so as to furnish enhanced metal-metal bonding. We thus searched for compounds LThThL with end-on coordinated neutral ligands L, which maintain the zero oxidation state. ${ }^{53,54,55}$ Tertiary phosphines $\left(\mathrm{PR}_{3}\right)$ are long established neutral Lewis base ligands which behave as electron pair donors. We therefore calculated the geometric and electronic structures of $\mathrm{R}_{3} \mathrm{PThThPR}_{3}(\mathrm{R}=\mathrm{H}, \mathrm{Me})$ using scalar relativistic density functional theory (DFT) at the generalised gradient approximation (GGA) level, and present valence MO energy level diagrams for $\mathrm{HThThH}_{2} \mathrm{Th}_{2}$ and $\mathrm{H}_{3} \mathrm{PThThPH}_{3}$ in Figure 1. HThThH has the expected $7 \mathrm{~s} \sigma_{\mathrm{g}}{ }^{2} 6 \mathrm{~d} \pi_{\mathrm{u}}{ }^{4}$ triple bond (labelled as $1 \sigma_{\mathrm{g}}{ }^{2} 1 \pi_{\mathrm{u}}{ }^{4}$ on Figure 1) and $\mathrm{Th}_{2}$ the triplet $7 \mathrm{~s} \sigma_{\mathrm{g}}{ }^{2} 6 \mathrm{~d} \pi_{\mathrm{u}}{ }^{4} 6 \mathrm{~d} \sigma_{\mathrm{g}}{ }^{1} 6 \mathrm{~d} \delta_{\mathrm{g}}{ }^{1}$ configuration $\left(1 \sigma_{\mathrm{g}}{ }^{2} 1 \pi_{\mathrm{u}}{ }^{4} 2 \sigma_{\mathrm{g}}{ }^{1} 1 \delta_{\mathrm{g}}{ }^{1}\right)$ reported previously. However, the introduction of the $\sigma$ donor phosphine ligands shifts the $2 \sigma_{\mathrm{g}}$ orbital up in energy, making it more favourable to place both of the unpaired electrons in the $1 \delta_{\mathrm{g}}$ orbitals, yielding the electronic configuration $7 \mathrm{~s} \sigma_{\mathrm{g}}{ }^{2} 6 \mathrm{~d} \pi_{\mathrm{u}}{ }^{4} 6 \mathrm{~d} \delta_{\mathrm{g}}{ }^{2}$ $\left(1 \sigma_{\mathrm{g}}{ }^{2} 1 \pi_{\mathrm{u}}{ }^{4} 1 \delta_{\mathrm{g}}{ }^{2}\right)$. The key orbital isosurfaces are shown in Figure 2. This new type of Th-Th quadruple bond with the two unpaired electrons in the $\delta$ bonding HOMO is shorter than any yet reported (2.607 $\AA)$, c. 0.04 and $0.09 \AA$ respectively shorter than those in $\mathrm{Th}_{2}(2.650 \AA)$ and triply bonded HThThH $(2.704 \AA)$. This shortening is most likely due to the differing directionality of the $6 \mathrm{~d} \delta$ and $6 \mathrm{~d} \sigma$ atomic orbitals, the latter being oriented along the Th-Th axis and the former being more perpendicular to this direction.

Natural bond orbital (NBO) analysis confirms the quadruple bond character of $\mathrm{H}_{3} \mathrm{PThThPH}_{3}$; the averaged compositions and occupations of the $\sigma, \pi$ and $\delta$ bonding NBOs are collected in Table 1. For the $\sigma$ NBOs, the contributions are significantly more s-based than $d$, with very little $f$, while the $\pi$ components are predominantly of $d$ character, with a little $f$ and no s contribution. The two $\alpha$-spin $\delta$ symmetry SOMOs are also mainly d-based. The electron localisation function (ELF) isosurfaces of $\mathrm{H}_{3} \mathrm{PThThPH}_{3}$ (Figure 3) show significant electron pair density along the Th-Th bond, with clear four-sided localisation around the Th-Th vector in the $\alpha$ spin electron density and ring localization for the $\beta$ electron density in that region. The different shapes of the $\alpha$ - and $\beta$-ELF surfaces support the existence of $\delta$ bonds formed by the two unpaired $\alpha$ spin electrons.

To verify the DFT results and probe further the electronic structure of $\mathrm{H}_{3} \mathrm{PThThPH}_{3}$, we turned to $a b$ initio post Hartree-Fock (HF) methods at the CASPT2 and CCSD(T) levels. For the former, we employed an active space of eight electrons in eight orbitals, consisting of the five bonding $\left(1 \sigma_{\mathrm{g}}, 1 \pi_{\mathrm{u}}\right.$ and $\left.1 \delta_{\mathrm{g}}\right)$ and three anti-bonding frontier orbitals $\left(1 \sigma_{\mathrm{u}}{ }^{*}\right.$ and $\left.1 \pi_{\mathrm{g}}{ }^{*}\right)$. Expanding the active space to include the $2 \sigma_{\mathrm{g}}$ and $1 \delta_{\mathrm{u}}{ }^{*}$ orbitals yielded natural orbital occupation numbers of $<0.03$ for these, indicating that the 8 electron, 8 orbital active space is sufficient. The Th-Th bond lengths, total and relative energies, electronic configurations and occupation numbers of the natural orbitals of the ground ${ }^{3} \mathrm{~B}_{\mathrm{g}}$ and first excited ${ }^{3} \mathrm{~B}_{\mathrm{u}}$ states are collected in Table 2 . The ${ }^{3} \mathrm{~B}_{\mathrm{g}}$ ground state has the two unpaired electrons occupying the two degenerate $1 \delta_{\mathrm{g}}$ bonding orbitals, and has a Th-Th bond length of $2.629 \AA$, significantly shorter than that of the first excited state $\left({ }^{3} \mathrm{~B}_{\mathrm{u}}, 2.695 \AA\right)$ which has the $1 \sigma_{\mathrm{g}}{ }^{2} 1 \pi_{\mathrm{u}}{ }^{4} 1 \delta_{\mathrm{g}}{ }^{1} 1 \sigma_{\mathrm{u}}{ }^{* 1}$ configuration. The energy gap between the two states is $44.52 \mathrm{~kJ} / \mathrm{mol}$, indicating a strong preference for the new type of ground state quadruple Th-Th bond suggested by the DFT calculations. 
Mindful that CASPT2 may not always yield accurate energy gaps, partly due to the lack of active space similarity after optimization of SCF and/or geometry, ${ }^{56}$ we performed $\operatorname{CCSD}(\mathrm{T})$ calculations on $\mathrm{H}_{3} \mathrm{PThThPH}_{3}$. The results are also presented in Table 2, from which it can be seen that the ground state is once again ${ }^{3} \mathrm{~B}_{\mathrm{g}}$, with a Th-Th distance almost identical to that obtained with CASPT2, and the same $1 \sigma_{\mathrm{g}}{ }^{2} 1 \pi_{\mathrm{u}}{ }^{4} 1 \delta_{\mathrm{g}}{ }^{2}$ configuration. $\operatorname{CCSD}(\mathrm{T})$ differs from CASPT2, however, in the energy of the first excited state, which is now of much lower relative energy than the first excited state at the CASPT2 level, albeit with the same electronic configuration and very similar Th-Th bond length.

To probe further the nature of the ground and low lying excited states, we have explored the effects of spin-orbit (SO) coupling on the scalar relativistic (SR) states of $\mathrm{H}_{3} \mathrm{PThThPH}_{3}$ with the $1 \delta_{\mathrm{g}}{ }^{2}$, $1 \delta_{\mathrm{g}}{ }^{1} 1 \sigma_{\mathrm{u}}{ }^{* 1}$ and $1 \sigma_{\mathrm{u}}{ }^{* 2}$ principal configurations of the two unpaired electrons. We are restricted to the $\mathrm{C}_{2 \mathrm{~h}}$ Abelian point group; the $1 \delta_{\mathrm{g}}$ orbitals transform as $\mathrm{a}_{\mathrm{g}}$ and $\mathrm{b}_{\mathrm{u}}$ and the $1 \sigma_{\mathrm{u}}{ }^{*}$ as $\mathrm{b}_{\mathrm{u}}$, leading to nine SR states derived from two electrons occupying three orbitals with both singlet and triplet multiplicities. The energies and symmetries of these are shown on the left hand side of Figure 4. Under SO coupling, these nine states split into fifteen ones, shown on the right hand side of Figure 4 and the eight lowest states are collected in Table 3. The SO coupled ground state is the $1 \mathrm{~A}_{\mathrm{g}}$, lying $9.42 \mathrm{~kJ} / \mathrm{mol}$ lower than the first excited $2 \mathrm{~A}_{\mathrm{g}}$ state. The $1 \delta_{\mathrm{g}}{ }^{2}$ configuration makes up essentially all of the ground state wavefunction, further confirming our conclusion that $\mathrm{H}_{3} \mathrm{PThThPH}_{3}$ has a new type of ground state quadruple $\mathrm{Th}-\mathrm{Th}$ bond. Furthermore, the three lowest energy excited states $\left(2 \mathrm{~A}_{\mathrm{g}}, 1 \mathrm{~B}_{\mathrm{g}}\right.$ and $\left.2 \mathrm{~B}_{\mathrm{g}}\right)$ are all $100 \% 1 \delta_{\mathrm{g}}{ }^{2}$.

Our new type of quadruple bond in $\mathrm{H}_{3} \mathrm{PThThPH}_{3}$ is realized by introducing end-on connected $\sigma$ donor $\mathrm{PH}_{3}$ ligands to the $\mathrm{Th}_{2}$ unit, shifting up the $2 \sigma_{\mathrm{g}}$ orbital, a conclusion consistent across density functional and $a b$ initio approaches. We have therefore explored the generality of the effect through further DFT studies of Th-Th systems with a variety of other neutral ligands. The optimised Th-Th distances are collected in Table 4, which also gives the electronic configuration of the least stable electrons. Note that most of the molecules investigated have a slightly trans-bent structure, ${ }^{57}$ with optimised $\angle_{\mathrm{L}-\mathrm{Th} \text {-Th }}$ angles ranging from $168^{\circ}$ to $180^{\circ}$. These angles are collected in Table S2, which also shows that the energy differences between the trans-bent and linear geometries are very small. Table 4 reveals that the Th-Th bond length is very sensitive to the nature of the ligands, ranging from 2.590 to $2.888 \AA$, and the electronic configuration also varies across the systems studied. Among the group 15-based ligands, $\mathrm{PR}_{3}(\mathrm{R}=\mathrm{H}, \mathrm{Me}, \mathrm{Cy}, \mathrm{Ph})$ and $\mathrm{AsH}_{3}$ all have a quadruple $\mathrm{Th}$-Th bond with the $1 \sigma_{\mathrm{g}}{ }^{2} 1 \pi_{\mathrm{u}}{ }^{4} 1 \delta_{\mathrm{g}}{ }^{2}$ configuration, whereas $\mathrm{NH}_{3}$ and the $\mathrm{N}$-heterocyclic carbene $\mathrm{C}(\mathrm{NHCH})_{2}\left(\mathrm{NHC}^{58}\right)$ yield a triple Th-Th bond with the $1 \sigma_{\mathrm{g}}{ }^{2} 1 \pi_{\mathrm{u}}{ }^{4} 1 \delta_{\mathrm{g}}{ }^{1} 1 \sigma_{\mathrm{u}}{ }^{* 1}$ configuration. $\mathrm{CO}$ and NO produce much longer $\mathrm{Th}-\mathrm{Th}$ distances, on account of significant $\pi$ back donation energetically lowering the two $6 \mathrm{~d}$-based $1 \pi_{\mathrm{g}}{ }^{*} \mathrm{Th}-$ Th antibonding orbitals to become the HOMO in both OCThThCO (Figure 5, Table 4) and ONThThNO, the latter compound featuring the longest Th-Th bond length found (2.888 $\AA$ ). Modifying the $\mathrm{PH}_{3}$ ligands with the introduction of one or two fluorine atoms also stabilises the $1 \pi_{\mathrm{g}}{ }^{*}$ orbitals, and the configurations can be tuned from $1 \delta_{\mathrm{g}}{ }^{2}$ to $1 \delta_{\mathrm{g}}{ }^{1} 1 \pi_{\mathrm{g}}{ }^{* 1}$ and $1 \pi_{\mathrm{g}}{ }^{* 2}$ on going from $\mathrm{L}=\mathrm{PH}_{3}$ to $\mathrm{PFH}_{2}$ and $\mathrm{PF}_{2} \mathrm{H}$ respectively.

In order to understand why the electronic configurations of the group 15 congenors $\mathrm{H}_{3} \mathrm{PThThPH}_{3}$ and $\mathrm{H}_{3} \mathrm{NThThNH}_{3}$ differ, we have analysed their $\mathrm{MO}$ compositions in terms of those of their constituent $\mathrm{L}_{2}$ and $\mathrm{Th}_{2}$ fragments. The results are presented in Table 5. The LUMO+1 $(-0.433 \mathrm{eV})$ and LUMO+7 $(2.500 \mathrm{eV})$ of the $\left(\mathrm{PH}_{3}\right)_{2}$ ligand fragment contribute $(7.23 \%$ and $2.96 \%$ respectively) to the $1 \sigma_{\mathrm{u}}{ }^{*} \mathrm{MO}$ of $\mathrm{H}_{3} \mathrm{PThThPH}_{3}(-2.153 \mathrm{eV})$, shifting it up in energy. By contrast, the LUMO+1 $(-0.341 \mathrm{eV})$ of the $\left(\mathrm{NH}_{3}\right)_{2}$ ligand fragment is less stable than its $\left(\mathrm{PH}_{3}\right)_{2}$ analogue, and contributes less $(5.99 \%)$ to 
the $1 \sigma_{\mathrm{u}}{ }^{*} \mathrm{MO}$ in $\mathrm{H}_{3} \mathrm{NThThNH}_{3}(-2.524 \mathrm{eV})$, such that this orbital is largely unaltered from that in $\mathrm{Th}_{2}$. Consequently, $\mathrm{H}_{3} \mathrm{PThThPH}_{3}$ adopts the $1 \delta_{\mathrm{g}}{ }^{2}$ configuration while $\mathrm{H}_{3} \mathrm{NThThNH}_{3}$ prefers $1 \delta_{\mathrm{g}}{ }^{1} 1 \sigma_{\mathrm{u}}{ }^{*}$.

Table 6 presents the Th-Th bond orders (BOs) for $\mathrm{H}_{3} \mathrm{PThThPH}_{3}$, calculated by several different approaches including the Quantum Theory of Atoms-in-Molecules (QTAIM) delocalisation indices $\delta$. Data for five other compounds, $\mathrm{H}_{3} \mathrm{AsThThAsH}_{3}, \mathrm{H}_{3} \mathrm{NThThNH}_{3}, \mathrm{HThThH}$, OCThThCO and ONThThNO, which span the range of computed Th-Th bond lengths, are also given. The absolute values of the BOs differ significantly over the various methods but, apart from Mayer, there is very strong correlation between $\mathrm{BO}$ and bond length as shown by the least-squares linear regression correlation coefficient $R^{2}{ }^{59}$ The range of computed BOs is significantly less than that of the formal values, but in all cases the ordering of the computed data matches that of the formal BOs.

In addition to that of $\mathrm{H}_{3} \mathrm{PThThPH}_{3}$, Table 1 presents NBO analysis of the five other compounds discussed in the previous paragraph. The data for $\mathrm{H}_{3} \mathrm{AsThThAsH} \mathrm{H}_{3}$ are very similar to the $\mathrm{PH}_{3}$ analogue, supporting the assignment of a quadruple bond. The expected triple bond is found for $\mathrm{H}_{3} \mathrm{NThThNH}_{3}$ and HThThH, consistent with the $1 \sigma_{\mathrm{g}}{ }^{2} 1 \pi_{\mathrm{u}}{ }^{4} 1 \delta_{\mathrm{g}} 1 \sigma_{\mathrm{u}}{ }^{* 1}$ configuration of the former two and $1 \sigma_{\mathrm{g}}{ }^{2} 1 \pi_{\mathrm{u}}{ }^{4}$ of the latter. The NBO data for OCThThCO and ONThThNO are also consistent with their Kohn-Sham MO configurations, $1 \sigma_{\mathrm{g}}{ }^{2} 1 \pi_{\mathrm{u}}{ }^{4} 1 \pi_{\mathrm{g}}{ }^{* 2}$ and $1 \sigma_{\mathrm{g}}{ }^{2} 1 \pi_{\mathrm{u}}{ }^{4} 1 \pi_{\mathrm{g}}{ }^{* 4}$ respectively. The former yields a formal double bond, and NBO analysis returns four Th-Th bonding electrons. In ONThThNO, the $1 \pi_{\mathrm{g}}{ }^{*}$ antibonding orbitals are full, leaving only a formal single bond produced by the two $1 \sigma_{\mathrm{g}}$ electrons, confirmed by the NBO analysis.

Table 7 collects several other QTAIM metrics for the six molecules, this time for the Th-Th bond critical point (BCP) electron $(\rho)$ and energy $(H)$ densities, and electron density Laplacian $\nabla^{2} \rho$. The relatively low $\rho$, negative $H$ and positive $\nabla^{2} \rho$ at the BCP are typical of metal-metal bonds. ${ }^{60}$ The former two parameters show good correlation with the Th-Th bond length, with $R^{2}$ values around 0.9 , providing evidence that in these thorium systems the BCP $\rho$ and $H$ data are good indicators of the metal-metal bond strength. ${ }^{61,62}$

Finally, we consider the thermodynamic stability of the LThThL motif. Table 8 presents the DFT optimised electronic and Gibbs energy differences between $\mathrm{LThThL}$ and $2 \mathrm{~L}+\mathrm{Th}_{2}$, this fragmentation having been chosen as one could in principle start from $\mathrm{Th}_{2}$ and $\mathrm{L}$ vapour in matrix isolation experiments. All of our LThThL compounds are more stable than their fragments at the $\Delta E$ level, and all bar $\mathrm{H}_{3} \mathrm{AsThThAsH}_{3}$ remain so at $\Delta G$. Furthermore, we note that the stability of the $\mathrm{PR}_{3}$ systems is greater for the larger R groups, hinting at a synthetic way forward to our new type of Th-Th quadruple bond.

\section{Conclusions}

In summary, quantum chemical calculations at both the DFT and post HF levels show that ground state $\mathrm{H}_{3} \mathrm{PThThPH} \mathrm{H}_{3}$ has a very short Th-Th quadruple bond (c. $2.6 \AA$ ) with a previously unreported electronic configuration featuring two unpaired electrons in $6 \mathrm{~d}$-based $\delta$ bonding orbitals. Replacing the $\mathrm{PH}_{3}$ ligands with ten other neutral groups allows us to tune the metal-metal bond from quadruple to triple, double and single, with lengths ranging from $2.590 \AA$ in $\mathrm{H}_{3} \mathrm{AsThThAsH}_{3}$ (the shortest Th-Th bond yet reported) to $2.888 \AA$ for ONThThNO. The $\mathrm{Th}_{2}$ motif is thus revealed as a highly sensitive probe of ligand electron donor/acceptor ability.

\section{Acknowledgements}


We are grateful to the University of Manchester for a postdoctoral research fellowship (to HSH) and for computational resources from the University's Computational Shared Facility. 
Figure 1. Scalar relativistic Kohn-Sham (PBE) valence energy levels of $\mathrm{HThThH}_{2} \mathrm{Th}_{2}$ and $\mathrm{H}_{3} \mathrm{PThThPH}_{3}$. Up and down arrows represent the electronic occupation of the frontier molecular orbitals. The Th-Th distances are shown at the foot of the figure.

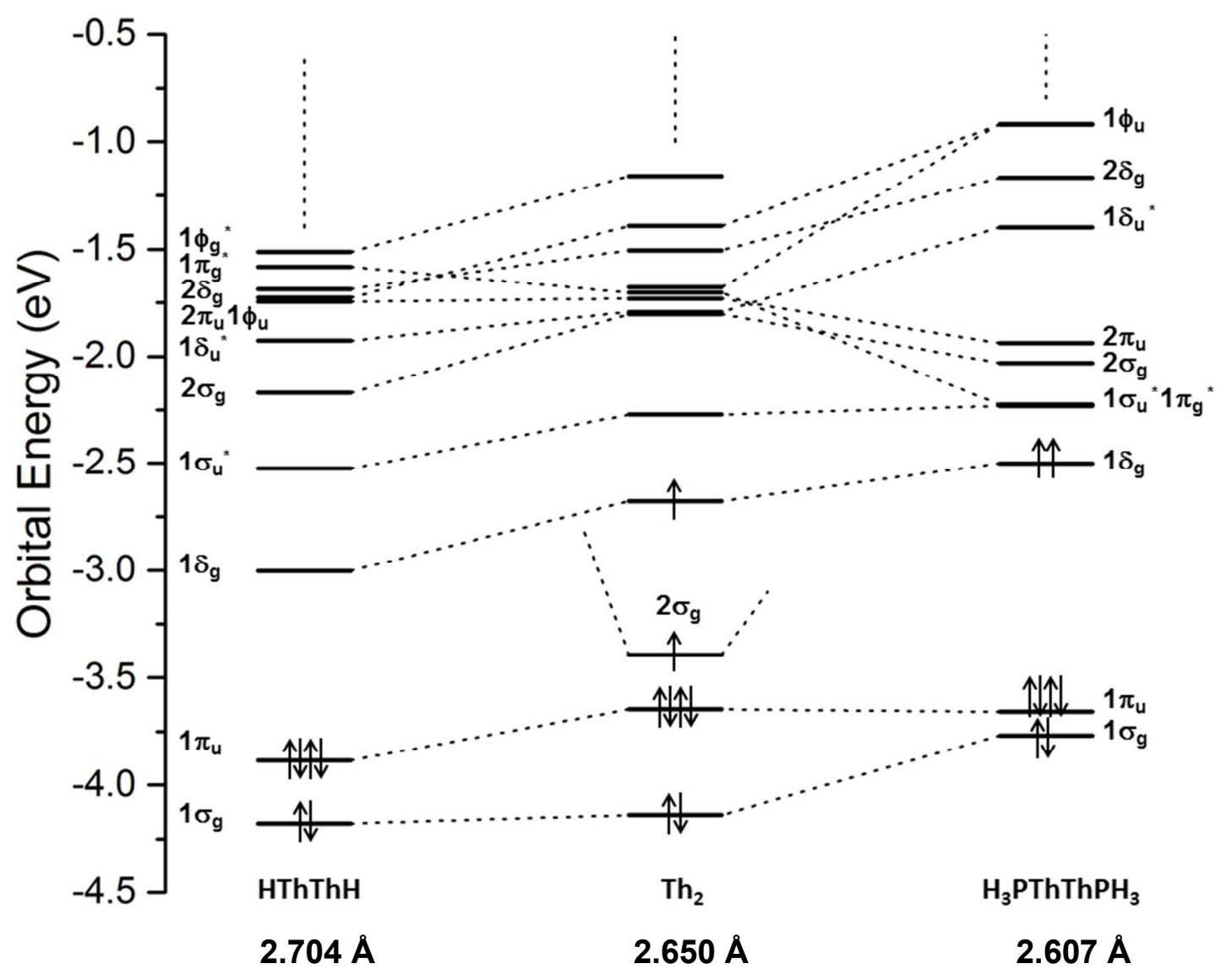


Figure 2. The frontier Kohn-Sham (PBE) valence orbitals of $\mathrm{H}_{3} \mathrm{PThThPH}_{3}$ (isosurface $=0.04$ a.u.) with the $1 \sigma_{\mathrm{g}}{ }^{2} 1 \pi_{\mathrm{u}}{ }^{4} 1 \delta_{\mathrm{g}}{ }^{2}$ electronic configuration with two $\alpha$ spin electrons in the two degenerate $1 \delta_{\mathrm{g}}$ orbitals. Note that only one MO is shown for each of the degenerate orbitals of $1 \pi_{\mathrm{u}}, 1 \pi_{\mathrm{g}}{ }^{*}, 1 \delta_{\mathrm{g}}, 1 \delta_{\mathrm{u}}{ }^{*}$ and $1 \phi_{\mathrm{u}}$ symmetries.

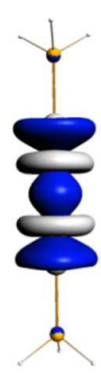

$2 \sigma_{g}$

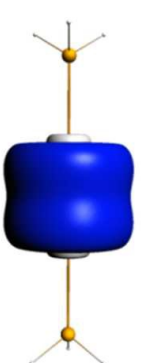

$1 \sigma_{g}$

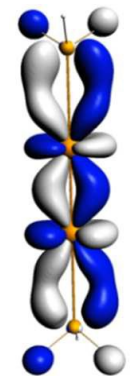

$2 \pi_{u}$

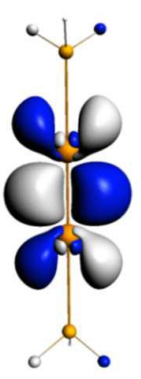

$1 \pi$

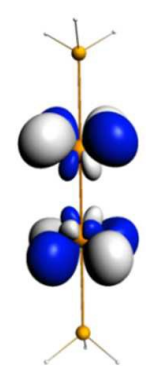

$1 \delta_{u}^{*}$

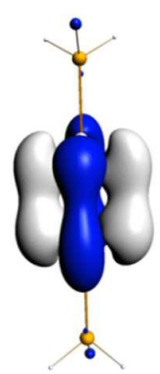

$1 \delta_{\mathrm{g}}$

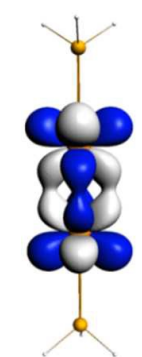

$2 \delta_{g}$

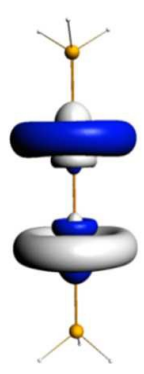

$1 \sigma_{u}^{*}$

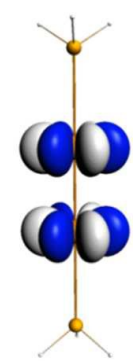

$1 \phi_{\mathrm{u}}$

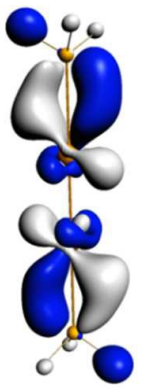

$1 \pi{ }_{g}^{*}$

Figure 3. The electron localisation function isosurfaces for $\alpha$ and $\beta$ electrons of $\mathrm{H}_{3} \mathrm{PThThPH}_{3}$ (isovalue $=0.5, \mathrm{PBE}$ DFT)

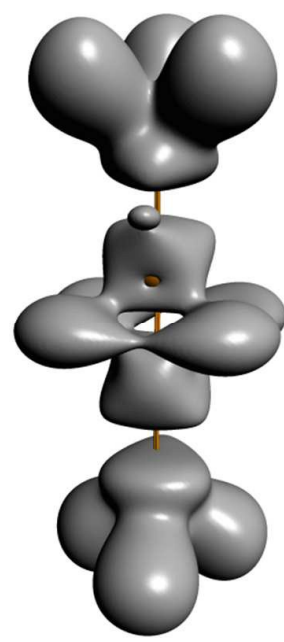

$(\alpha)$

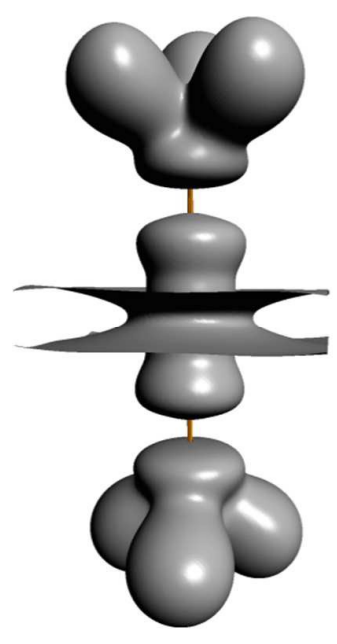

$(\beta)$ 
Figure 4. Energy level diagram for the ground and lowest excited states of $\mathrm{H}_{3} \mathrm{PThThPH}_{3}$ at the $\mathrm{CASSCF} / \mathrm{CCSD}(\mathrm{T}) /$ spin-orbit (SO) level. SR state energies from $\mathrm{CCSD}(\mathrm{T})$ single-point energies.

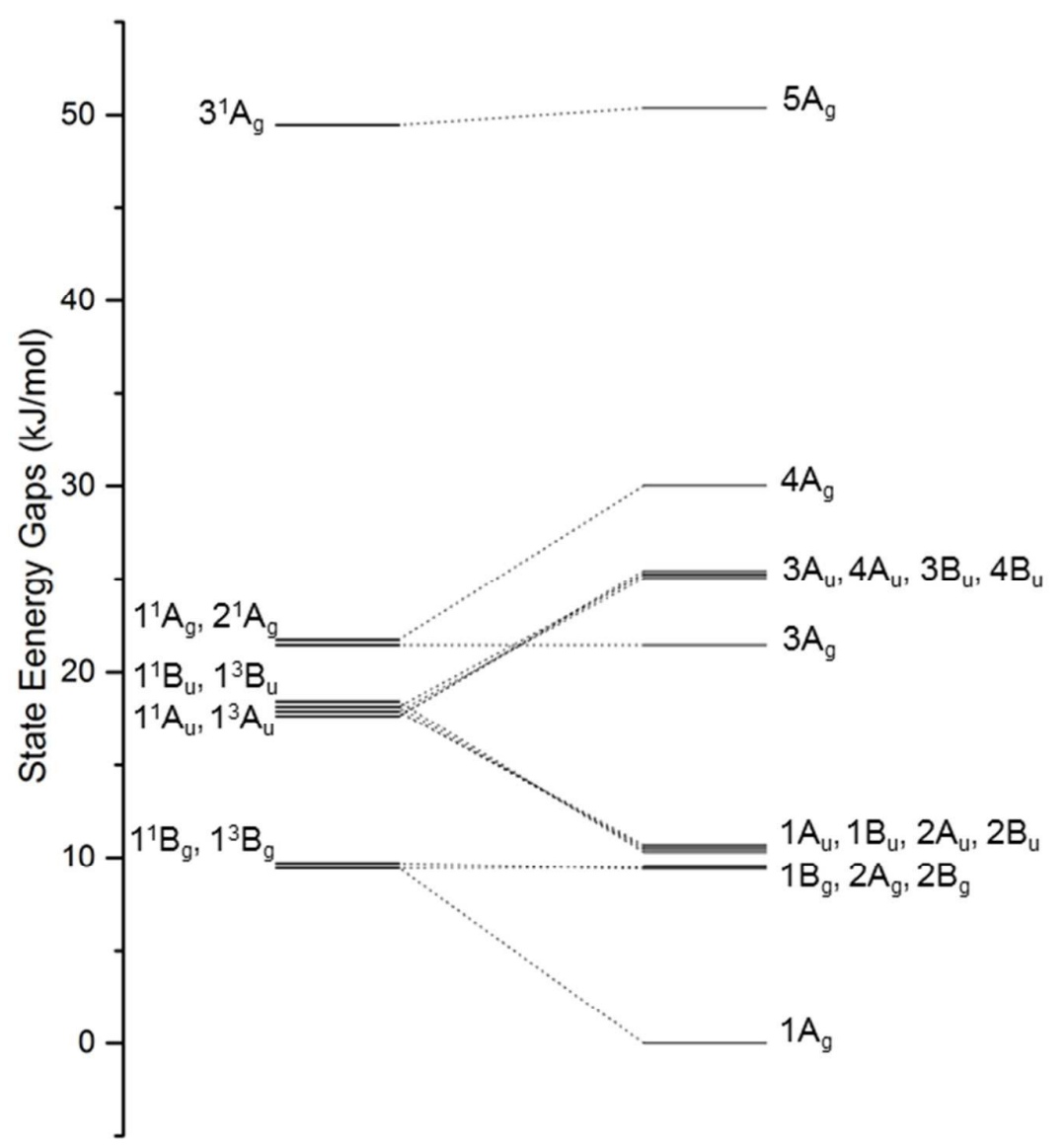


Figure 5. Scalar relativistic Kohn-Sham (PBE) valence energy levels of $\mathrm{OCThThCO}, \mathrm{Th}_{2}$ and $\mathrm{H}_{3} \mathrm{PThThPH}_{3}$. Up and down arrows represent the electronic occupation of the frontier molecular orbitals.

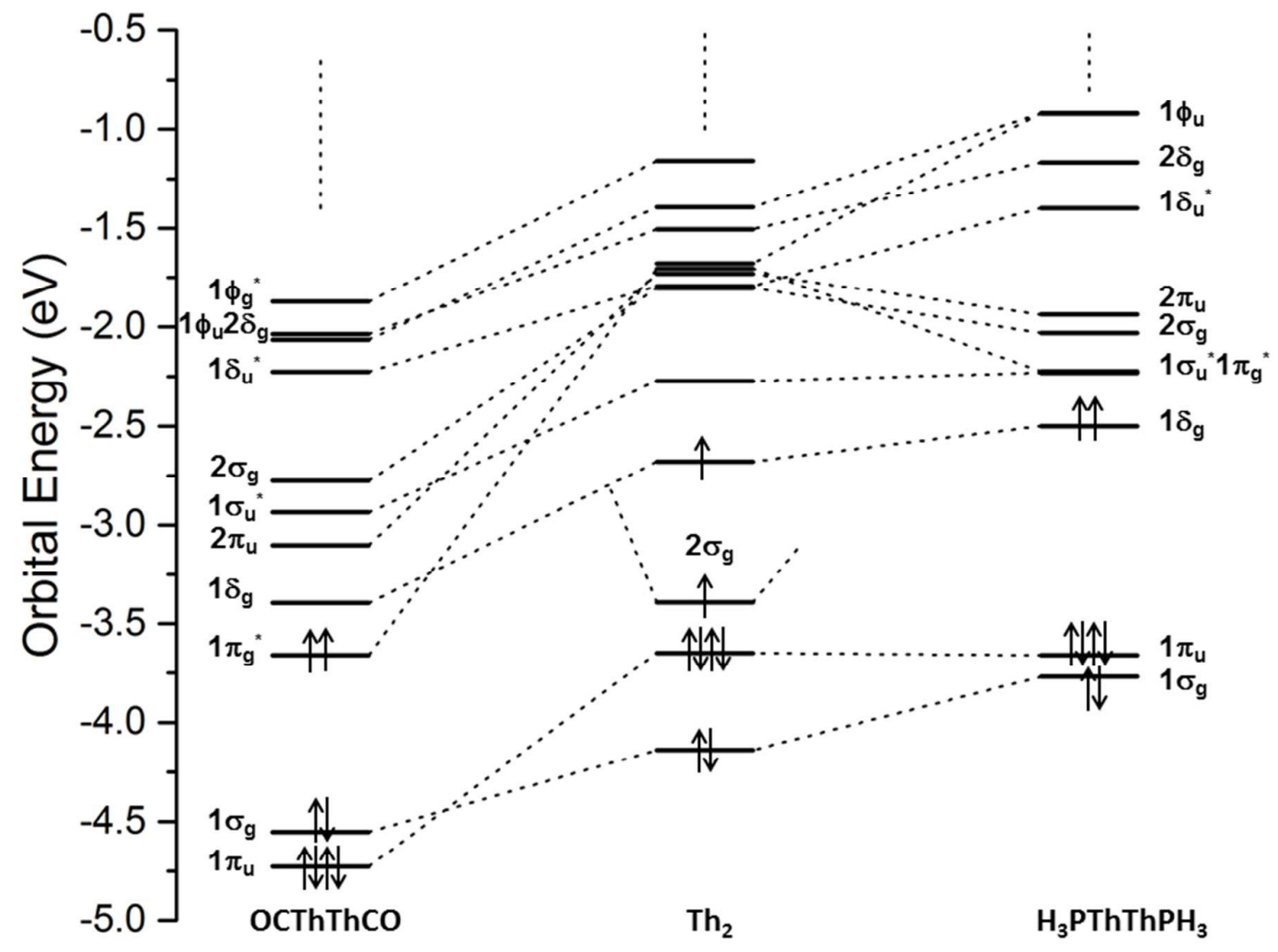


Table 1. Occupations and compositions of selected NBOs (PBE) of LThThL compounds ( $\mathrm{L}=\mathrm{PH}_{3}, \mathrm{NH}_{3}, \mathrm{AsH}_{3}, \mathrm{CO}$, $\mathrm{NO}$ and $\left.\mathrm{H}\right)$. Where an atomic orbital contribution is listed without a following superscripted number, this implies a superscripted 1.00 . Thus $\mathrm{df}^{0.09}$, for example, means $\mathrm{d}^{1.00} \mathrm{f}^{0.09}$. The other superscripted numbers in the same parentheses are relative to the atomic orbital with the implied 1.00.

\begin{tabular}{|c|c|c|c|c|}
\hline Compound & Occ & $\alpha$ spin & Occ & $\beta$ spin \\
\hline \multirow[t]{5}{*}{$\mathrm{H}_{3} \mathrm{PThThPH}_{3}$} & 0.77 & $50 \% \operatorname{Th}\left(\mathrm{df}^{0.09}\right)+50 \% \operatorname{Th}\left(\mathrm{df}^{0.09}\right)(\delta)$ & & \\
\hline & 0.89 & $50 \% \operatorname{Th}\left(\mathrm{df}^{0.08}\right)+50 \% \operatorname{Th}\left(\mathrm{df}^{0.08}\right)(\delta)$ & & \\
\hline & 0.94 & $50 \% \operatorname{Th}\left(\mathrm{df}^{0.09}\right)+50 \% \operatorname{Th}\left(\mathrm{df}^{0.09}\right)(\pi)$ & 0.93 & $50 \% \operatorname{Th}\left(\mathrm{df}^{0.11}\right)+50 \% \operatorname{Th}\left(\mathrm{df}^{0.11}\right)(\pi)$ \\
\hline & 0.97 & $50 \% \operatorname{Th}\left(\mathrm{df}^{0.08}\right)+50 \% \operatorname{Th}\left(\mathrm{df}^{0.08}\right)(\pi)$ & 0.93 & $50 \% \operatorname{Th}\left(\mathrm{df}^{0.12}\right)+50 \% \operatorname{Th}\left(\mathrm{df}^{0.12}\right)(\pi)$ \\
\hline & 1.00 & $50 \% \operatorname{Th}\left(\mathrm{sd}^{0.19} \mathrm{f}^{0.07}\right)+50 \% \operatorname{Th}\left(\mathrm{sd}^{0.19} \mathrm{f}^{0.07}\right)(\sigma)$ & 0.99 & $50 \% \operatorname{Th}\left(\mathrm{sd}^{0.21} \mathrm{f}^{0.09}\right)+50 \% \operatorname{Th}\left(\mathrm{sd}^{0.21} \mathrm{f}^{0.09}\right)(\sigma)$ \\
\hline \multirow{5}{*}{$\mathrm{H}_{3} \mathrm{AsThThAsH}_{3}$} & 0.78 & $50 \% \operatorname{Th}\left(\mathrm{df}^{0.08}\right)+50 \% \operatorname{Th}\left(\mathrm{df}^{0.08}\right)(\delta)$ & & \\
\hline & 0.90 & $50 \% \operatorname{Th}\left(\mathrm{df}^{0.09}\right)+50 \% \operatorname{Th}\left(\mathrm{df}^{0.09}\right)(\delta)$ & & \\
\hline & 0.95 & $50 \% \operatorname{Th}\left(\mathrm{df}^{0.10}\right)+50 \% \operatorname{Th}\left(\mathrm{df}^{0.10}\right)(\pi)$ & 0.93 & $50 \% \operatorname{Th}\left(\mathrm{df}^{0.12}\right)+50 \% \operatorname{Th}\left(\mathrm{df}^{0.12}\right)(\pi)$ \\
\hline & 1.00 & $50 \% \operatorname{Th}\left(\mathrm{df}^{0.08}\right)+50 \% \operatorname{Th}\left(\mathrm{df}^{0.08}\right)(\pi)$ & 0.93 & $50 \% \operatorname{Th}\left(\mathrm{df}^{0.13}\right)+50 \% \operatorname{Th}\left(\mathrm{df}^{0.13}\right)(\pi)$ \\
\hline & 1.00 & $50 \% \operatorname{Th}\left(\mathrm{sd}^{0.18} \mathrm{f}^{0.07}\right)+50 \% \operatorname{Th}\left(\mathrm{sd}^{0.18} \mathrm{f}^{0.07}\right)(\sigma)$ & 0.99 & $50 \% \operatorname{Th}\left(\mathrm{sd}^{0.19} \mathrm{f}^{0.08}\right)+50 \% \operatorname{Th}\left(\mathrm{sd}^{0.19} \mathrm{f}^{0.08}\right)(\sigma)$ \\
\hline \multirow[t]{3}{*}{$\mathrm{H}_{3} \mathrm{NThThNH}_{3}$} & 1.00 & $50 \% \operatorname{Th}\left(\mathrm{df}^{0.15}\right)+50 \% \operatorname{Th}\left(\mathrm{df}^{0.15}\right)(\pi)$ & 1.00 & $50 \% \operatorname{Th}\left(\mathrm{df}^{0.19}\right)+50 \% \operatorname{Th}\left(\mathrm{df}^{0.19}\right)(\pi)$ \\
\hline & 1.00 & $50 \% \operatorname{Th}\left(\mathrm{df}^{0.15}\right)+50 \% \operatorname{Th}\left(\mathrm{df}^{0.15}\right)(\pi)$ & 1.00 & $50 \% \operatorname{Th}\left(\mathrm{df}^{0.19}\right)+50 \% \operatorname{Th}\left(\mathrm{df}^{0.19}\right)(\pi)$ \\
\hline & 1.00 & $50 \% \operatorname{Th}\left(\mathrm{df}^{0.03}\right)+50 \% \operatorname{Th}\left(\mathrm{df}^{0.03}\right)(\delta)$ & 0.99 & $50 \% \operatorname{Th}\left(\mathrm{sd}^{0.14} \mathrm{f}^{0.02}\right)+50 \% \operatorname{Th}\left(\mathrm{sd}^{0.14} \mathrm{f}^{0.02}\right)(\sigma)$ \\
\hline \multirow[t]{3}{*}{ HThThH } & 2.00 & $50 \% \operatorname{Th}\left(\mathrm{df}^{0.16}\right.$ & $+50 \%$ & $\operatorname{Th}\left(\mathrm{df}^{0.16}\right)(\pi)$ \\
\hline & 2.00 & $50 \% \operatorname{Th}\left(\mathrm{df}^{0.16}\right.$ & $+50 \%$ & $\operatorname{Th}\left(\mathrm{df}^{0.16}\right)(\pi)$ \\
\hline & 1.96 & $50 \% \operatorname{Th}\left(\mathrm{sd}^{0.36} \mathrm{f}^{0.04}\right.$ & $+50 \%$ & $\operatorname{Th}\left(\mathrm{sd}^{0.36} \mathrm{f}^{0.04}\right)(\sigma)$ \\
\hline \multirow[t]{3}{*}{ OCThThCO } & & & 0.94 & $50 \% \operatorname{Th}\left(\mathrm{df}^{0.16}\right)+50 \% \operatorname{Th}\left(\mathrm{df}^{0.16}\right)(\pi)$ \\
\hline & & & 0.94 & $50 \% \operatorname{Th}\left(\mathrm{df}^{0.16}\right)+50 \% \operatorname{Th}\left(\mathrm{df}^{0.16}\right)(\pi)$ \\
\hline & 0.99 & $50 \% \operatorname{Th}\left(\mathrm{sd}^{0.32} \mathrm{f}^{0.06}\right)+50 \% \operatorname{Th}\left(\mathrm{sd}^{0.32} \mathrm{f}^{0.06}\right)(\sigma)$ & 0.99 & $50 \% \operatorname{Th}\left(\mathrm{sd}^{0.31} \mathrm{f}^{0.07}\right)+50 \% \operatorname{Th}\left(\mathrm{sd}^{0.31} \mathrm{f}^{0.07}\right)(\sigma)$ \\
\hline ONThThNO & 1.98 & \multicolumn{3}{|c|}{$50 \% \operatorname{Th}\left(\mathrm{sd}^{0.22} \mathrm{f}^{0.06}\right)+50 \% \operatorname{Th}\left(\mathrm{sd}^{0.22} \mathrm{f}^{0.06}\right)(\sigma)$} \\
\hline
\end{tabular}


Table 2. Occupation numbers (ONs) of the natural orbitals from CASPT2 $(8 \mathrm{e}, 8 \mathrm{o})$ calculations of the ground ${ }^{3} \mathrm{~B}_{\mathrm{g}}$ and first excited ${ }^{3} \mathrm{~B}_{\mathrm{u}}$ states of $\mathrm{H}_{3} \mathrm{PThThPH}_{3}$ in $D_{3 \mathrm{~d}}$ symmetry. The total and relative energies of the two states are provided, as are the optimised Th-Th bond lengths. $\operatorname{CCSD}(\mathrm{T})$ data for the ground ${ }^{3} \mathrm{~B}_{\mathrm{g}}$ and first excited ${ }^{3} \mathrm{~B}_{\mathrm{u}}$ states in italics.

\begin{tabular}{ccc}
\hline State & ${ }^{3} \mathrm{~B}_{\mathrm{g}}$ & ${ }^{3} \mathrm{~B}_{\mathrm{u}}$ \\
Configuration & $1 \sigma_{\mathrm{g}}{ }^{2} 1 \pi_{\mathrm{u}}{ }^{4} 1 \delta_{\mathrm{g}}{ }^{*}$ & $1 \sigma_{\mathrm{g}}{ }^{2} 1 \pi_{\mathrm{u}}{ }^{4} 1 \delta_{\mathrm{g}}{ }^{1} 1 \sigma_{\mathrm{u}}{ }^{* 1}$ \\
$\mathrm{ON}\left(1 \pi_{\mathrm{g}}{ }^{*}\right)$ & 0.12 & 0.10 \\
$\mathrm{ON}\left(1 \sigma_{\mathrm{u}}{ }^{*}\right)$ & 0.10 & 1.02 \\
$\mathrm{ON}\left(1 \delta_{\mathrm{g}}\right)$ & 0.98 & 0.03 \\
$\mathrm{ON}\left(1 \delta_{\mathrm{g}}\right)$ & 1.00 & 1.01 \\
$\mathrm{ON}\left(1 \pi_{\mathrm{u}}\right)$ & 3.86 & 3.87 \\
$\mathrm{ON}\left(1 \sigma_{\mathrm{g}}\right)$ & 1.94 & 1.98 \\
\hline$E(\mathrm{H})$ & $-1498.17646 /-1498.24087$ & $-1498.15951 /-1498.23876$ \\
$\Delta E(\mathrm{~kJ} / \mathrm{mol})$ & 0.00 & $44.52 / 5.52$ \\
$\mathrm{Th}-\mathrm{Th}(\AA)$ & $2.629 / 2.619$ & $2.695 / 2.691$ \\
\hline
\end{tabular}


Table 3. Relative energies and scalar relativistic compositions of the ground and excited spin-orbit coupled $(\mathrm{SOC})$ states of $\mathrm{H}_{3} \mathrm{PThThPH}_{3}$ at the $\mathrm{CASSCF} / \mathrm{CCSD}(\mathrm{T}) / \mathrm{SO}$ level at the CASPT2(8e, 8o)-optimised ground state geometry.

\begin{tabular}{|c|c|c|}
\hline SOC state & $\Delta E(\mathrm{~kJ} / \mathrm{mol})$ & Contributing SR states (\%) and the principal configurations of the two unpaired electrons \\
\hline $2 \mathrm{~B}_{\mathrm{u}}$ & 10.53 & $24.78{ }^{1} \mathrm{~B}_{\mathrm{u}}\left(1 \delta_{\mathrm{g}}{ }^{1} 1 \sigma_{\mathrm{u}}{ }^{* 1}\right)+25.03^{3} \mathrm{~A}_{\mathrm{u}}\left(1 \delta_{\mathrm{g}}{ }^{1} 1{\sigma_{\mathrm{u}}}^{*}\right)+25.10^{3} \mathrm{~A}_{\mathrm{u}}\left(1 \delta_{\mathrm{g}}{ }^{1} 1{\sigma_{\mathrm{u}}}^{*}\right)+25.09^{3} \mathrm{~B}_{\mathrm{u}}\left(1 \delta_{\mathrm{g}}{ }^{1} 1 \sigma_{\mathrm{u}}{ }^{* 1}\right)$ \\
\hline $2 \mathrm{~A}_{\mathrm{u}}$ & 10.53 & $24.78{ }^{1} \mathrm{~A}_{\mathrm{u}}\left(1 \delta_{\mathrm{g}}{ }^{1} 1 \sigma_{\mathrm{u}}{ }^{* 1}\right)+25.10{ }^{3} \mathrm{~A}_{\mathrm{u}}\left(1 \delta_{\mathrm{g}}{ }^{1} 1 \sigma_{\mathrm{u}}{ }^{* 1}\right)+25.03{ }^{3} \mathrm{~B}_{\mathrm{u}}\left(1 \delta_{\mathrm{g}}{ }^{1} 1 \sigma_{\mathrm{u}}{ }^{* 1}\right)+25.09^{3} \mathrm{~B}_{\mathrm{u}}\left(1 \delta_{\mathrm{g}}{ }^{1} 1 \sigma_{\mathrm{u}}{ }^{* 1}\right)$ \\
\hline $1 B_{u}$ & 10.45 & $25.22{ }^{1} \mathrm{~B}_{\mathrm{u}}\left(1 \delta_{\mathrm{g}}{ }^{1} 1 \sigma_{\mathrm{u}}{ }^{* 1}\right)+24.97{ }^{3} \mathrm{~A}_{\mathrm{u}}\left(1 \delta_{\mathrm{g}}{ }^{1} 1 \sigma_{\mathrm{u}}{ }^{*}\right)+24.91{ }^{3} \mathrm{~A}_{\mathrm{u}}\left(1 \delta_{\mathrm{g}}{ }^{1} 1 \sigma_{\mathrm{u}}{ }^{* 1}\right)+24.90{ }^{3} \mathrm{~B}_{\mathrm{u}}\left(1 \delta_{\mathrm{g}}{ }^{1} 1 \sigma_{\mathrm{u}}{ }^{* 1}\right)$ \\
\hline $1 \mathrm{~A}_{\mathrm{u}}$ & 10.45 & $25.22{ }^{1} \mathrm{~A}_{\mathrm{u}}\left(1 \delta_{\mathrm{g}}{ }^{1} 1 \sigma_{\mathrm{u}}{ }^{* 1}\right)+24.91{ }^{3} \mathrm{~A}_{\mathrm{u}}\left(1 \delta_{\mathrm{g}}{ }^{1} 1 \sigma_{\mathrm{u}}{ }^{* 1}\right)+24.97{ }^{3} \mathrm{~B}_{\mathrm{u}}\left(1 \delta_{\mathrm{g}}{ }^{1} 1{\sigma_{\mathrm{u}}}^{* 1}\right)+24.90{ }^{3} \mathrm{~B}_{\mathrm{u}}\left(1 \delta_{\mathrm{g}}{ }^{1} 1 \sigma_{\mathrm{u}}{ }^{* 1}\right)$ \\
\hline $2 \mathrm{~B}_{\mathrm{g}}$ & 9.47 & $50.00{ }^{1} \mathrm{~B}_{\mathrm{g}}\left(1 \delta_{\mathrm{g}}^{2}\right)+50.00{ }^{3} \mathrm{~B}_{\mathrm{g}}\left(1 \delta_{\mathrm{g}}^{2}\right)$ \\
\hline $2 \mathrm{~A}_{\mathrm{g}}$ & 9.42 & $100{ }^{3} \mathrm{~B}_{\mathrm{g}}\left(1 \delta_{\mathrm{g}}^{2}\right)$ \\
\hline $1 \mathrm{~B}_{\mathrm{g}}$ & 9.38 & $50.00{ }^{1} \mathrm{~B}_{\mathrm{g}}\left(1 \delta_{\mathrm{g}}^{2}\right)+50.00{ }^{3} \mathrm{~B}_{\mathrm{g}}\left(1 \delta_{\mathrm{g}}^{2}\right)$ \\
\hline $1 \mathrm{~A}_{\mathrm{g}}$ & 0.00 & $70.34{ }^{3} \mathrm{~B}_{\mathrm{g}}\left(1 \delta_{\mathrm{g}}^{2}\right)+28.76{ }^{1} \mathrm{~A}_{\mathrm{g}}\left(1 \delta_{\mathrm{g}}^{2}\right)+0.90{ }^{1} \mathrm{~A}_{\mathrm{g}}\left(1{\sigma_{\mathrm{u}}}^{* 2}\right)$ \\
\hline
\end{tabular}


Table 4. DFT (PBE) optimised Th-Th bond lengths and electronic configurations of the studied LThThL compounds. All are triplets except for ONThThNO, which is a singlet. Note that although some of the $\angle{ }_{\text {L-Th-Th }}$ angles are slightly less than $180^{\circ}$, the electronic configurations are given in linear symmetry notation.

\begin{tabular}{|c|c|c|}
\hline Compounds & Th-Th $(\AA)$ & Configuration \\
\hline $\mathrm{H}_{3} \mathrm{AsThThAsH}_{3}$ & 2.590 & $1 \sigma_{\mathrm{g}}^{2} 1 \pi_{\mathrm{u}}^{4} 1 \delta_{\mathrm{g}}^{2}$ \\
\hline $\mathrm{H}_{3} \mathrm{PThThPH}_{3}$ & 2.607 & $1 \sigma_{\mathrm{g}}{ }^{2} 1 \pi_{\mathrm{u}}{ }^{4} 1 \delta_{\mathrm{g}}^{\mathrm{g}}$ \\
\hline $\mathrm{Me}_{3} \mathrm{PThThPMe}_{3}$ & 2.601 & $1 \sigma_{\mathrm{g}}{ }^{2} 1 \pi_{\mathrm{u}}{ }^{4} 1 \delta_{\mathrm{g}}{ }^{2}$ \\
\hline $\mathrm{Cy}_{3} \mathrm{PThThPCy}_{3}$ & 2.607 & $1 \sigma_{\mathrm{g}}^{2} 1 \pi_{\mathrm{u}}{ }^{4} 1 \delta_{\mathrm{g}}^{2}$ \\
\hline $\mathrm{Ph}_{3} \mathrm{PThThPPh}_{3}$ & 2.633 & $1 \sigma_{\mathrm{g}}{ }^{2} 1 \pi_{\mathrm{u}}{ }^{4} 1 \delta_{\mathrm{g}}{ }^{2}$ \\
\hline $\mathrm{H}_{3} \mathrm{NThThNH}_{3}$ & 2.648 & $1 \sigma_{\mathrm{g}}{ }^{2} 1 \pi_{\mathrm{u}}^{4} 1 \delta_{\mathrm{g}}{ }^{1} 1 \sigma_{\mathrm{u}}{ }^{* 1}$ \\
\hline NHCThThNHC & 2.676 & $1 \sigma_{\mathrm{g}}{ }^{2} 1 \pi_{\mathrm{u}}{ }^{4} 1 \delta_{\mathrm{g}}{ }^{1} 1 \sigma_{\mathrm{u}}{ }^{* 1}$ \\
\hline $\mathrm{H}_{2} \mathrm{FPThThPFH}_{2}$ & 2.664 & $1 \sigma_{\mathrm{g}}{ }^{2} 1 \pi_{\mathrm{u}}{ }^{4} 1 \pi_{\mathrm{g}}{ }^{* 1} 1 \delta_{\mathrm{g}}{ }^{1}$ \\
\hline $\mathrm{HF}_{2} \mathrm{PThThPF}_{2} \mathrm{H}$ & 2.698 & $1 \sigma_{\mathrm{g}}^{2} 1 \pi_{\mathrm{u}}^{4} 1 \pi_{\mathrm{g}}{ }^{{ }^{2}}$ \\
\hline OCThThCO & 2.766 & $1 \sigma_{\mathrm{g}}{ }^{2} 1 \pi_{\mathrm{u}}{ }^{4} 1 \pi_{\mathrm{g}}{ }^{* 2}$ \\
\hline ONThThNO & 2.888 & $1 \sigma_{\mathrm{g}}{ }^{2} 1 \pi_{\mathrm{u}}{ }^{4} 1 \pi_{\mathrm{g}}{ }^{* 4}$ \\
\hline
\end{tabular}

Table 5. The energy and compositions of the frontier MOs (PBE) of LThThL $\left(\mathrm{L}=\mathrm{NH}_{3}, \mathrm{PH}_{3}\right)$ based on fragment analysis using $\mathrm{Th}_{2}$ and $\mathrm{L}_{2}$ fragments.

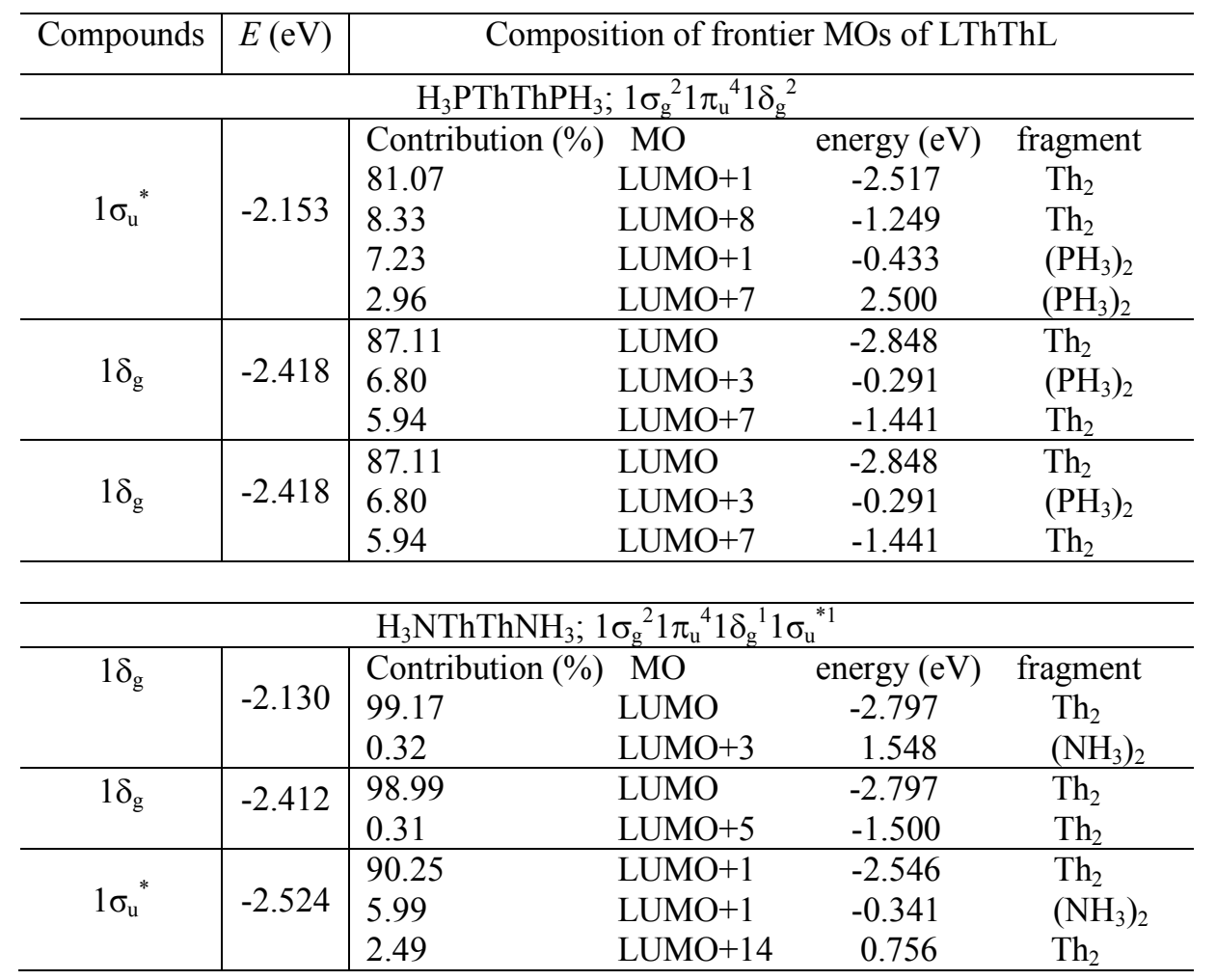


Table 6. DFT (PBE) bond orders (BOs) for selected compounds with Th-Th bonds, calculated using the Mayer, Gopinathan-Jug and Wiberg approaches, and also the QTAIM delocalisation indices $(\delta)$. The formal bond orders are also given. $R^{2}$ values are for the linear correlation of calculated bond order with Th-Th distance.

\begin{tabular}{ccccccc}
\hline & $\mathrm{Th}-\mathrm{Th}(\AA)$ & $\mathrm{BO}_{\text {Mayer }}$ & $\mathrm{BO}_{\mathrm{G}-\mathrm{J}}$ & $\mathrm{BO}_{\text {Wiberg }}$ & $\delta(\mathrm{Th}, \mathrm{Th})$ & BO $_{\text {Formal }}$ \\
\hline $\mathrm{H}_{3} \mathrm{AsThThAsH}_{3}$ & 2.590 & 3.203 & 4.043 & 3.815 & 3.539 & 4 \\
$\mathrm{H}_{3} \mathrm{PThThPH}_{3}$ & 2.607 & 3.104 & 3.998 & 3.766 & 3.522 & 4 \\
$\mathrm{H}_{3} \mathrm{NThThNH}_{3}$ & 2.648 & 2.472 & 3.565 & 3.159 & 3.327 & 3 \\
HThThH & 2.704 & 2.989 & 3.340 & 3.207 & 3.150 & 3 \\
OCThThCO & 2.766 & 2.571 & 2.764 & 2.696 & 2.667 & 2 \\
ONThThNO & 2.888 & 2.190 & 2.189 & 2.192 & 2.146 & 1 \\
$R^{2}$ & & 0.581 & 0.981 & 0.928 & 0.983 & \\
\hline
\end{tabular}

Table 7. Quantum Theory of Atoms-in-Molecules Th-Th bond critical point electron $(\rho)$ and energy densities $(H)$, and electron density Laplacian $\left(\nabla^{2} \rho\right)$, from PBE densities, for several LThThL compounds (in atomic units). $R^{2}$ values are for the linear correlation of the QTAIM metrics with ThTh distance.

\begin{tabular}{ccccc}
\hline & Th-Th $(\AA)$ & $\rho$ & $H$ & $\nabla^{2} \rho$ \\
\hline $\mathrm{H}_{3} \mathrm{AsThThAsH}_{3}$ & 2.590 & 0.092 & -0.030 & 0.396 \\
$\mathrm{H}_{3} \mathrm{PThThPH}_{3}$ & 2.607 & 0.088 & -0.026 & 0.389 \\
$\mathrm{H}_{3} \mathrm{NThThNH}_{3}$ & 2.648 & 0.074 & -0.022 & 0.219 \\
HThThH & 2.704 & 0.078 & -0.024 & 0.281 \\
OCThThCO & 2.766 & 0.068 & -0.017 & 0.274 \\
ONThThNO & 2.888 & 0.054 & -0.010 & 0.200 \\
$R^{2}$ & & 0.893 & 0.903 & 0.461 \\
\hline
\end{tabular}

Table 8. DFT (PBE) electronic $(\Delta E)$ and Gibbs $(\Delta G)$ energy differences $(\mathrm{kJ} / \mathrm{mol})$ for the reactions $\mathrm{Th}_{2}(\mathrm{~g})+2 \mathrm{~L}(\mathrm{~g}) \rightarrow \mathrm{LThThL}(\mathrm{g})$.

\begin{tabular}{|c|c|c|}
\hline Compounds & $\Delta E$ & $\Delta G$ \\
\hline $\mathrm{H}_{3} \mathrm{AsThThAsH}_{3}$ & -58.9 & 29.2 \\
\hline $\mathrm{H}_{3} \mathrm{PThThPH}_{3}$ & -89.0 & -6.2 \\
\hline $\mathrm{Me}_{3} \mathrm{PThThPMe}_{3}$ & -144.8 & -47.2 \\
\hline $\mathrm{Cy}_{3} \mathrm{PThThPCy}$ & -187.2 & -67.5 \\
\hline $\mathrm{Ph}_{3} \mathrm{PThThPPh}_{3}$ & -175.4 & -52.7 \\
\hline $\mathrm{H}_{3} \mathrm{NThThNH}_{3}$ & -140.3 & -63.5 \\
\hline NHCThThNHC & -261.7 & -169.5 \\
\hline $\mathrm{H}_{2} \mathrm{FPThThPFH}_{2}$ & -722.7 & -622.1 \\
\hline $\mathrm{HF}_{2} \mathrm{PThThPF}_{2} \mathrm{H}$ & -174.3 & -85.3 \\
\hline OCThThCO & -245.9 & -152.9 \\
\hline ONThThNO & -565.1 & -479.4 \\
\hline
\end{tabular}


1 G. Frenking, S. Shaik, The Chemical Bond: Chemical Bonding Across the Periodic Table, $1^{\text {st }}$ ed., Wiley-VCH, Weinheim, 2014.

2 F. R. Wagner, A. Noor, R. Kempe, Nat. Chem., 2009, 1, 529-536.

3 H. A. Spinney, N. A. Piro, C. C. Cummins, J. Am. Chem. Soc., 2009, 131, 16233-16243.

4 P. F. Souter, G. P. Kushto, L. Andrews, M. Neurock, J. Am. Chem. Soc., 1997, 119, 1682-1687.

5 L. Gagliardi, B. O. Roos, Nature, 2005, 433, 848-851.

6 T. W. Hayton, Chem. Commun., 2013, 49, 2956-2973.

7 H. S. Hu, Y. H. Qiu, X. G. Xiong, W. H. Schwarz, J. Li, Chem. Sci., 2012, 3, 2786-2796.

8 S. T. Liddle, Angew. Chem. Int. Ed., 2014, 54, 8604-8641.

9 F. A. Cotton, G. Wilkinson, C. A. Murillo, M. Bochmann, Advanced Inorganic Chemistry, 6nd ed., WileyInterscience, New York, 1999.

10 W. J. Liu, W. Kuchle, M. Dolg, Phys. Rev. A, 1998, 58, 1103-1110.

11 M. R. MacDonald, M. E. Fieser, J. E. Bates, J. W. Ziller, F. Furche, W. J. Evans, J. Am. Chem. Soc., 2013, 135, 13310-13313.

12 H. S. La Pierre, A. Scheurer, F. W. Heinemann, W. Hieringer, K. Meyer, Angew. Chem. Int. Ed., 2014, 53, 7158-7162.

13 G. Wang, M. Zhou, J. T. Goettel, G. J. Schrobilgen, J. Su, J. Li, T. Schlöder, S. Riedel, Nature, 2014, 514, 475-477.

14 Q. Zhang, S. X. Hu, H. Qu, J. Su, G. Wang, J. B. Lu, M. Chen, M. Zhou, J. Li, Angew. Chem. Int. Ed., 2016, 55, 6896-6900.

15 B. Vlaisavljevich, P. L. Diaconescu, W. L. Lukens, L. Gagliardi, C. C. Cummins, Organometallics, 2013,32 , 1341-1352

16 D. E. Smiles, G. Wu, N. Kaltsoyannis, T. W. Hayton, Chem. Sci., 2015, 6, 3891-3899.

17 N. Kaltsoyannis, Inorg. Chem. 2013, 52, 3407-3413.

18 S. T. Liddle, Angew. Chem. Int. Ed. 2014, 53, 6696-6700.

19 M. S. Dutkiewicz, J. H. Farnaby, C. Apostolidis, E. Colineau, O. Walter, N. Magnani, M. G. Gardiner, J. B.

Love, N. Kaltsoyannis, R. Caciuffo, P. L. Arnold, Nat. Chem. 2016, 8, 797-802.

20 A. R. Fox, P. L. Arnold, C. C. Cummins, J. Am. Chem. Soc., 2010, 132, 3250-3251.

21 B. O. Roos, P. Malmqvist, L. Gagliardi, J. Am. Chem. Soc., 2006, 128, 17000-17006.

22 M. Straka, P. Pyykkö, J. Am. Chem. Soc., 2005, 127, 13090-13091.

23 G. La Macchia, M. Brynda, L. Gagliardi, Angew. Chem. Int. Ed., 2006, 45, 6210-6213.

24 L. Gagliardi, P. Pyykkö, B. O. Roos, Phys. Chem. Chem. Phys., 2005, 7, 2415-2417.

25 G. Cavigliasso, N. Kaltsoyannis, Inorg. Chem., 2007, 46, 3557-3565.

26 G. Cavigliasso, N. Kaltsoyannis, Inorg. Chem., 2006, 45, 6828-6839.

27 B. O. Roos, L. Gagliardi, Inorg. Chem., 2006, 45, 803-807.

28 J. Zhou, J. L. Sonnenberg, H. B. Schlegel, Inorg. Chem., 2010, 49, 6545-6551.

29 C. Z. Wang, J. K. Gibson, J. H. Lan, Q. Y. Wu, Y. L. Zhao, J. Li, Z. F. Chai, W. Q. Shi, Dalton Trans., 2015 , 44, 17045-17053.

30 T. Steimle, D. L. Kokkin, S. Muscarella, J. Phys. Chem., A 2015, 119, 9281-9285.

31 J. P. Perdew, K. Burke, M. Ernzerhof, Phys. Rev. Lett., 1996, 77, 3865-3868.

32 ADF, 2014.01, SCM, Theoretical Chemistry, Vrijie Universiteit, Amsterdam, The Netherlands, (http://www.scm.com).

33 E. van Lenthe, E. J. Baerends, J. Comput. Chem., 2003, 24, 1142-1156.

34 E. van Lenthe, E. J. Baerends, J. G. Snijders, J. Chem. Phys., 1993, 99, 4597-4610. 
35 J. D. Watts, J. Gauss, R. J. Bartlett, J. Chem. Phys., 1993, 98, 8718-8733.

36 R. J. Bartlett, M. Musial, Rev. Mod. Phys., 2007, 79, 291-352.

37 P. J. Knowles, H. J. Werner, Chem. Phys. Lett., 1985, 115, 259-267.

38 H. J. Werner, Mol. Phys., 1996, 89, 645-661.

39 P. Celani, H. J. Werner, J. Chem. Phys., 2000, 112, 5546-5557.

40 H. J. Werner, et al. MOLPRO, version 2015.1, Univ. College Cardiff Consultants Limited, Cardiff, U.K., http://www.molpro.net.

41 A. Malmqvist, B. O. Roos, B. Schimmelpfennig, Chem. Phys. Lett., 2002, 357, 230-240.

42 B. O. Roos, P. A. Malmqvist, Phys. Chem. Chem. Phys., 2004, 6, 2919-2927.

43 W. Kuechle, M. Dolg, H. Stoll, H. Preuss, J. Chem. Phys., 1994, 100, 7535-7542.

44 X. Cao, M. Dolg, H. Stoll, J. Chem. Phys., 2003, 118, 487-496.

45 X. Cao, M. Dolg, J. Molec. Struct. (Theochem), 2004, 673, 203-209.

46 T. H. Dunning, Jr. J. Chem. Phys., 1989, 90, 1007-1023.

47 D. E. Woon, T.H. Dunning, Jr. J. Chem. Phys., 1993, 98, 1358-1371.

48 A. K. Wilson, D. E. Woon, K. A. Peterson, T. H. Dunning, Jr., J. Chem. Phys., 1999, 110, 7667-7676.

49 A. E. Reed, L. A. Curtiss, F. Weinhold, Chem. Rev., 1988, 88, 899-926.

50 B. Silvi, A. Savin, Nature, 1994, 371, 683-686.

51 F. Bader, Atoms in Molecules: A Quantum Theory; OUP: Oxford, 1990.

52 M. J. Frisch, et al. Gaussian09, Revision A.1 ed., Gaussian, Inc., Wallingford CT, 2009.

53 D. Tofan, C. C. Cummins, Chem. Sci., 2012, 3, 2474-2478.

54 J. L. Dutton, G. Frenking, Angew. Chem. Int. Ed., 2016, 55, 13380-13382.

55 M. Arrowsmith, H. Braunschweig, M. A. Celik, T. Dellermann, R. D. Dewhurst, W. C. Ewing, K. Hammond, T. Kramer, I. Krummenacher, J. Mies, K. Radacki, J. K. Schuster, Nat. Chem., 2016, 8, 890-894.

56 M. F. Rode, H. J. Werner, Theor. Chem. Acc., 2005, 114, 309-317.

57 M. Lein, A. Krapp, G. Frenking, J. Am. Chem. Soc., 2005, 127, 6290-6299.

58 R. Tonner, G. Heydenrych, G. Frenking, Chem. Asian J., 2007, 2, 1555-1567.

59 A. R. E. Mountain, N. Kaltsoyannis. Dalton Trans., 2013, 42, 13477-13486.

60 J. A. Hlina, J. R. Pankhurst, N. Kaltsoyannis, P. L. Arnold, J. Am. Chem. Soc., 2016, 138, 3333-3345.

61 R. J. Boyd, Chem. Phys. Lett., 1985, 120, 80-85.

62 Q. R. Huang, J. R. Kingham, N. Kaltsoyannis. Dalton Trans., 2015, 44, 2554-2566. 


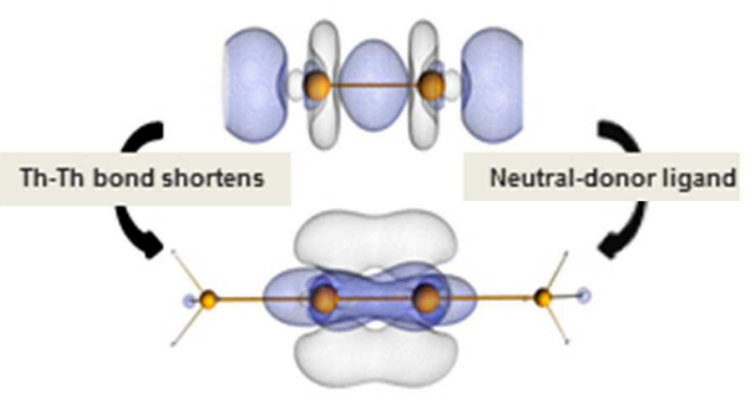

79×39mm (96 x 96 DPI) 